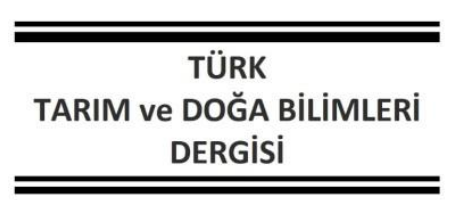

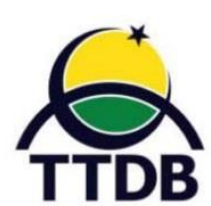

www.dergipark.gov.tr/turkjans

Araştırma Makalesi

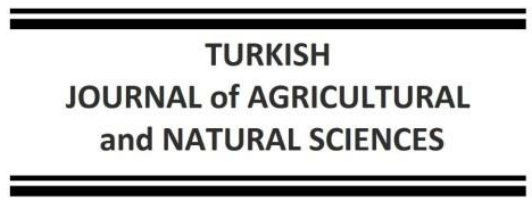
.

\title{
Farklı Tuz Uygulamalarının Makarnalık (Triticum durum L.) Buğdayda Kadmiyum ve Çinko Alımı Üzerine Etkisi
}

\author{
Faruk ÖZKUTLU \\ Ordu Üniversitesi, Ziraat Fakültesi, Toprak Bilimi ve Bitki Besleme Bölümü
*Sorumlu Yazar: farukozkutlu@hotmail.com
}

Geliş Tarihi: 08.04.2020 Düzeltme Geliş Tarihi: 08.10.2020 Kabul Tarihi: 13.10.2020

Öz

Değişik kaynaklardan topraklara ulaşan ve önemli bir çevre kirletici olan kadmiyum (Cd), bitki, hayvan ve insanların beslenmesinde mutlak gerekli bir element değildir. Kadmiyum, yüksek konsantrasyonlarda bulunduğunda, bitki, hayvan ve insanlara toksik etkisi olan bir elementtir. Bitkilerde Cd birikimini etkileyen önemli faktörlerden birisi toprakların tuzluluk durumudur. Bu araştırmada, değişik tuzların bitkilerde Cd birikimini nasıl etkilediği belirlenmiştir. Toprağa artan oranda $\mathrm{NaCl}, \mathrm{Na}_{2} \mathrm{SO}_{4}$ ve $\mathrm{CaCl}_{2}$ uygulandığında bitkilerin yalnızca $\mathrm{Cl}^{-}$formundaki tuzlarda ve özellikle $\mathrm{NaCl}$ ile $\mathrm{Cd}$ biriktirme kapasitesinde artışların olduğu saptanmıştır. Artan miktarlarda uygulanan değişik $\left(\mathrm{NaCl}, \mathrm{Na}_{2} \mathrm{SO}_{4}\right.$ ve $\left.\mathrm{CaCl}_{2}\right)$ tuzlardan $\mathrm{NaCl}$ tuzunun yeşil aksam $\mathrm{Cd}$ konsantrasyonunda çarpıcı biçimde artış oluşturduğu bulunmuştur. Değişik tuzların Cd alımı üzerine etkilerinin kıyaslanmasıyla $\mathrm{Cl}^{-}$tuzunun uygulandığı koşullarda, yeşil aksam Cd konsantrasyonu $\mathrm{SO}_{4}{ }^{-2}$ tuzu uygulanan bitkilere göre daha yüksek olmuştur. Tuzun $\mathrm{NaCl}$ ve $\mathrm{CaCl}_{2}$ formlarında uygulanması durumunda da bitkilerin $\mathrm{Cd}$ konsantrasyonu farklı şekilde etkilenmiştir. Klorürün Cd konsantrasyonu üzerindeki arttırıcı etkisi kendisini daha çok $\mathrm{Na}$ formunda uygulandı̆̆ında göstermiştir. Kalsiyum varlığında Cl'nın Cd alımı üzerinde Na iyonuna göre daha az arttırıcı etkisinin olduğu saptanmıştır. Sonuçlar, artan Cd ve farklı tuzların uygulanmasıyla yeşil aksam kuru madde verimini azalttığı ve bitki bünyesinde daha fazla Cd’yi biriktirdiği belirlenmiştir.

Anahtar kelimeler: Makarnalık buğday, $\mathrm{NaCl}, \mathrm{NaSO}_{4}, \mathrm{CaCl}_{2}$, kadmiyum

\section{Effect of Different Salt Treatments on Cadmium and Zinc Uptake in Durum Wheat (Triticum durum L.)}

\begin{abstract}
Cadmium (Cd), an important environmental polluter reaching into soils from different sources, is not an essential element in animal and human nutrition. Cadmium, when present in high concentrations, is an element with toxic effect to humans, animals and plants. One of the important factors affecting Cd accumulation in plants is salinity status of the soils. In this study, it was determined how different salts effected $\mathrm{Cd}$ accumulation in plants. When increasing rates of $\mathrm{NaCl}, \mathrm{Na}_{2} \mathrm{SO}_{4}$ and $\mathrm{CaCl}_{2}$ applied into the soil, it was determined that $\mathrm{Cd}$ accumulation capacity of the plants increased only with the forms of $\mathrm{Cl}^{-1}$ salts, particularly with $\mathrm{NaCl}$. It was found that, among different salts applied with increasing ratios $\left(\mathrm{NaCl}, \mathrm{Na}_{2} \mathrm{SO}_{4}\right.$ ve $\left.\mathrm{CaCl} 2\right), \mathrm{NaCl}$ salt remarkably increased green part $\mathrm{Cd}$ concentration. With comparing the effects of different salts on $\mathrm{Cd}$ uptake, green part $\mathrm{Cd}$ concentration in the $\mathrm{Cl}^{-1}$ salt applied condition was higher than those of the plants treated with $\mathrm{SO}_{4}{ }^{-2}$ salt. The $\mathrm{Cd}$ concentration of the plants was affected differently when the salt was applied as $\mathrm{NaCl}$ and $\mathrm{CaCl}_{2}$ forms. The increasing effect of chlorine on $\mathrm{Cd}$ concentration mostly occurred when it was applied as $\mathrm{Na}$ form. With the present of calcium, the increasing effect of $\mathrm{Cl}$ on $\mathrm{Cd}$ uptake was less comparing to $\mathrm{Na}$ ion. In conclusion, the application of $\mathrm{Cd}$ and different salts with increasing rates decreased dry matter yield of green part but increased Cd accumulation by plant.
\end{abstract}

Key words: Durum wheat, $\mathrm{NaCl}, \mathrm{NaSO}_{4}, \mathrm{CaCl}_{2}$, cadmium 


\section{Giriş}

Ağır metaller başlıca çevresel kirleticiler olmasının yanı sıra toksisite oluşturması nedeniyle canlılar için önemli bir beslenme ve çevresel sorun olarak güncelliğini korumaktadır. Toprakların ağır metallerle kirlenmesi sonucunda yalnızca toprak kalitesinin azalması değil aynı zamanda bitki sağlığı ve ürün verimliliği de olumsuz etkilenmektedir (Özkutlu ve ark., 2009). İnsanlar için ağır metallerin tamamı tehlikeli olup besin zinciriyle insanlara çok kolay geçişi olmaktadır. Ağır metallerden kadmiyum ( $\mathrm{Cd}$ ) toprakta diğer ağır metallerden farklı olarak çok fazla mobil olması nedeniyle düşük konsantrasyonlarda bile farklı bitki türlerinin hücreleri tarafından kolayca alınmakta ve birikebilmektedir (Moral, 2002; Quinn ve ark., 2011, Korkmaz ve ark., 2018). Kadmiyum bitki kökleri tarafından alındıktan sonra kolayca yeşil aksama taşınabilmektedir (Adams ve ark., 2004; Clemens, 2006).

Topraklara Cd girişi özellikle antroponejik kaynaklardan atmosfer yoluyla, tarım arazilerine kanalizasyon çamurunun uygulanması yoluyla ve fosforlu gübreleme yoluyla olmaktadır (Kılıç ve Korkmaz 2012). Topraklardaki Cd dinamiği; toprağın $\mathrm{pH}$, redoks durumu, organik madde içeriği, tekstür, hidro oksitler ve serbest karbonatlar ve tuzluluk gibi özellikler tarafından güçlü bir şekilde etkilenmektedir. Bitkilerde $\mathrm{Cd}$ birikimini etkileyen en önemli faktör toprakların tuzluluk durumudur. Topraklarda tuzluluğun artışıyla (özellikle $\mathrm{Cl}$ konsantrasyonunun artışıyla) bitkilerde Cd miktarının arttığı saptanmıştır (Norvell ve ark., 2000). Toprak tuzluluğu bitkisel üretim için önemli abiyotik streslerden birisi olup tuzlu topraklarda yetiştirilen bitkilerin ciddi verim kayıp kayıplarına maruz kaldıkları bilinmektedir (Uyanık ve ark., 2014; Ekbic ve ark., 2017). Tuzluluğun toprakta Cd'un hareketliliğini arttırması ve kompleks oluşturması sonucunda Cd'un bitkiler tarafından kolayca alınmasına neden olduğu ileri sürülmektedir. Toprak çözeltideki $\mathrm{Cl}^{-}$ konsantrasyonuna bağlı olarak $\mathrm{Cd}^{\prime}$ un $\mathrm{Cl}^{-}$ile değişik formları $\left(\mathrm{CdCl}^{+}, \mathrm{CdCl}_{2}, \mathrm{CdCl}_{3}^{-}\right.$ve $\left.\mathrm{CdCl}_{4}^{-2}\right)$ bulunmaktadır (Lindsay, 1979). Ayrıca, tuzlu toprakların çözelti kimyasında baskın bulunan $\mathrm{Cd}$, $\mathrm{Cl}^{\prime} u n$ bilinmeyen $\mathrm{CdCl}_{n}{ }^{2-n}$ formunu oluşturduğu düşünülmektedir. Sulama suyunun (özellikle $\mathrm{Cl}^{-}$ konsantrasyonu) kalitesi de bitkilerin Cd alımını etkilemektedir. McLaughlin ve ark. (1997) yaptığı bir araştırmada yukarıda vurgulanan sulama suyundaki $\mathrm{Cl}^{-}$konsantrasyonunun bitkilerin $\mathrm{Cd}$ alımı üzerinde etkili olabileceğini vurgulamıştır. McLaughlin ve ark. (1994) ticari bitkisel ürünlerde tuzluluğun $\quad \mathrm{Cd}$ konsantrasyonunu arttığını kanıtlamak için sulama suyunda $\mathrm{Cl}^{-}$ilavesi yapmış ve bitkilerin $\mathrm{Cd}$ konsantrasyonunda artan tuzluluğa bağıı olarak önemli oranda arttığını göstermiştir. Kadmiyum $\mathrm{Cl}^{-}$ile yaptığı kompleksler sonucunda Cd'un katyon değiştirici yüzeylere tutunması azalmakta ve böylece bitkilerce alınma şansının daha fazla olduğu düşünülmektedir. WegglerBeaton ve ark. (2000) hektara 50 ton bitkisel atık uygulaması yaptıktan sonra şeker pancarı ve buğday bitkisinde $\mathrm{NaCl}$ tuzunun $\mathrm{Cd}$ alımına etkisini araştırmış ve bu amaçla ortama sulama suyuyla $27.4 \mathrm{mM} \mathrm{NaCl}$ ilavesi sonucunda, her iki bitkinin yeşil aksamında meydana gelen $\mathrm{Cd}$ konsantrasyonundaki artıştan sadece toprak çözeltisindeki $\mathrm{Cd}^{+2}$ iyonunun aktivitesinin sorumlu olmadı̆̆ı; bu artışta, $\mathrm{Cd}^{\prime}$ nin $\mathrm{Cl}^{-}$komplekslerinin de etkili olduğu bildirilmiştir. Beslenmemizde büyük rol oynayan buğday $\mathrm{Cd}^{\prime} \mathrm{u}$ kolayca absorbe edebilmektedir. Tahıllar içerisinde makarnalık buğdayların ekmeklik buğdaylara göre tanelerinde daha fazla kadmiyum biriktirdiği çeşitli araştırmalarla saptanmıştır (Hart ve ark., 2002; Greger ve Löfsted ,2004; Shentu ve ark., 2008; Özkutlu, ve Kara, 2019). Çeşitli gıdalarla Cd'un insanlarda fazlaca biriktiğinde akciğer, karaciğer, böbrek rahatsızlığı, hipertansiyon gibi çok ciddi sağlık sorunlarına yol açtığı ifade edilmektedir (Gallego ve ark., 2012; Korkmaz ve ark., 2010). Kadmiyum, besin zinciri yoluyla insanlar tarafından alınması nedeniyle birçok ülke yenilebilir bitkilerde maksimum izin verilebilir $\mathrm{Cd}$ sınırı belirlemiştir (Bernard, 2008). Dünya Sağıık Örgütü (WHO) ve Bileşmiş Milletler Gıda ve Tarım Örgütü (FAO) tahıllarda izin verilebilir maksimum $\mathrm{Cd}$ konsantrasyonunu $0.1 \mathrm{mg} \mathrm{kg}^{-1}$ olarak belirlemiştir (WHO/FAO, 2001). WHO ile FAO insanların her bir kg vücut ağırlıklarına göre günlük tolere edebileceği

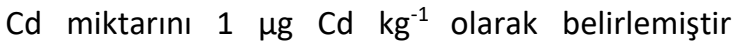
(Gawalko ve ark., 2001; Gray ve ark., 2001). Ancak, daha sonraki yıllarda Avrupa Komisyonu (EEC, 2001) buğday için maksimum izin verilebilir Cd sınır değerini $200 \mathrm{mg} \mathrm{kg}^{-1} \mathrm{FW}$ (taze ağırlık) olarak revize etmiştir. Söz konusu taze ağırlık değer $235 \mathrm{mg} \mathrm{kg}^{-1}$ DW (kuru ağırlık)'a eşit durumdadır. Greger ve Landberg, (2008) Avrupada insanlara besin zinciri vasıtasıyla $\mathrm{Cd}$ girişinin olduğunu ve insanlara $\mathrm{Cd}$ girişinin yaklaşık olarak \%40'ının tahıllar grubundan kaynaklandığının tahmin edildiğini açıklamıştır. Dünyada insanların beslenmesinin ana kaynağının buğday olduğu bilinmektedir. Son yıllarda bitkisel gıdalarda Cd birikimin nedenlerinin belirlenmesine yönelik araştırmalara hız verilmesinin yanısıra bitkisel ürünlerde $\mathrm{Cd}$ birikimine sebep olan faktörlerinde belirlenmesi çalışmaları artmaktadır.

Bu araştırmada da makarnalık buğdayda farklı tuzların Cd alımları üzerine etkisi araştırılmıştır. 
Materyal ve Metot

Sera denemesinde kullanılan toprak ve bitki materyali

Araştırmada kullanılan toprak EskişehirSultanönü yöresinden getirtilmiştir. Toprak, havada kurutulup $4 \mathrm{~mm}$ 'lik elekten geçirildikten sonra kullanılmıştır. Kullanılan toprak materyalinin analiz değerleri Çizelge 1'de verilmiştir. Araştırma, Çukurova Üniversitesi Ziraat Fakültesi Toprak Bölümü Araştırma Seralarında yürütülmüştür. Denemede, bitki materyali olarak makarnalık buğday (Diyarbakır-81) çeşidi kullanılmıştır. Araştırmanın sonuçları, Excel paket programı yardımıyla istatistik analizine tabi tutulmuştur.

Çizelge 1. Araştırma toprağının bazı fiziksel ve kimyasal özellikleri.

\begin{tabular}{lc}
\hline Özellikler ve Metodlar & Düzey \\
\hline Tekstür sınıfı, Bouyoucous (1952) & Killi (C) \\
pH Jackson (1959) & 8.08 \\
Tuz (mmhos/cm), U.S. Salinity Loboratory Staff (1954) & 0.22 \\
Organik madde (\%), Jackson (1959) & 0.7 \\
Kireç (\%), Çağlar (1949) & 14.02 \\
DTPA-Zn (mg kg-1), Lindsay ve Norvell (1978) & 0.1 \\
DTPA-Cd (mg kg-1), Lindsay ve Norvell (1978) & 0.005 \\
Toplam Zn (mg kg-1), Schlichting ve Blume (1966) & 51 \\
Toplam Cd (mg kg-1), Schlichting ve Blume (1966) & 0.27 \\
\hline
\end{tabular}

Saksı denemesinin kurulması ve yürütülmesi Plastik saksılarda (2 L'lik) $1.650 \mathrm{~kg}$ toprak tartılmış ve temel gübreler tüm saksılara $200 \mathrm{mg}$ $\mathrm{kg}^{-1} \mathrm{~N}\left\{\mathrm{Ca}\left(\mathrm{NO}_{3}\right)_{2} .4 \mathrm{H}_{2} \mathrm{O}\right\}, 100 \mathrm{mg} \mathrm{kg}^{-1} \mathrm{P}\left\{\mathrm{KH}_{2} \mathrm{PO}_{4}\right\}, 2.5$ $\mathrm{mg} \mathrm{kg}{ }^{-1} \mathrm{Fe}$ (Fe-EDTA) ve $1.0 \mathrm{mg} \mathrm{kg}^{-1} \mathrm{Zn}\left(\mathrm{ZnSO}_{4}\right.$. $\left.7 \mathrm{H}_{2} \mathrm{O}\right)$ uygulanmıştır. Deneme, $\mathrm{Cd}^{\prime}$ nin $(0,0.2$ ve $1.0 \mathrm{mg} \mathrm{Cd}\left(\mathrm{CdSO}_{4}\right)_{3} .8 \mathrm{H}_{2} \mathrm{O} \mathrm{kg}{ }^{-1}$ - toprak) dozları ve tuzların ( $\mathrm{NaCl}, \mathrm{Na}_{2} \mathrm{SO}_{4}$ ve $\mathrm{CaCl}_{2}$ ) 2 farklı dozu uygulanarak 3 tekerrürlü olarak 63 saksıda yürütülmüştür. Değişik tuz uygulamalarında $\mathrm{NaCl}$, 200 ve $1000 \mathrm{mg} \mathrm{NaCl} \mathrm{kg}^{-1} ; \mathrm{Na}_{2} \mathrm{SO}_{4}, 100$ ve $500 \mathrm{mg}$ $\mathrm{Na}_{2} \mathrm{SO}_{4} \mathrm{~kg}^{-1}$ ve $\mathrm{CaCl}_{2} 100$ ve $500 \mathrm{mg} \mathrm{CaCl} \mathrm{kg}^{-1}$ olarak tuzlarda $\mathrm{Cl}^{-}$anyonu ve $\mathrm{Na}^{+}$katyonu eşit miktarda olacak şekilde hesaplanıp verilmiştir. Deneme, tesadüf parselleri deneme desenine göre 3 tekerrürlü olarak yürütülmüştür. Bitkiler $\mathrm{Cd}$ ve tuz toksisitesi semptomları dikkate alınarak 45 gün süre ile yetiştirilmiş ve yeşil aksam hasadı yapılmıştır. Yeşil aksam örnekleri 70 o $C^{\prime}$ de etüvde 48 saat kurutulup öğütülmüştür. Yeşil aksam örneklerinde $\mathrm{Cd}$ ölçümü yapmak için örneklerden 0.25 gram alınarak $2 \mathrm{ml}$ saf su, $2 \mathrm{ml} \mathrm{H}_{2} \mathrm{O}_{2}$ (\%30'luk) ve $4 \mathrm{ml} \mathrm{HNO}_{3}$ (\%65'lik) içeren bir karışımı içinde mikro dalgada yakılmıştır (Milestone, Italya). Örneklerde Cd ölçümü ICP-AES (Inductively Coupled Plasma-Atomic Emmission Spectrometer; JY 138 Ultrace) ile Zn konsantrasyonu ise AAS (Atomik Absorbsiyon Cihazı; Varian-FS 220) ile belirlenmiştir.

\section{Bulgular ve Tartışma}

Yeşil aksam kuru madde üretimi

Bitkilerin $\mathrm{Cd}$ alımı üzerine farklı formlarda uygulanan $\left(\mathrm{Cl}^{-}\right.$ve $\mathrm{SO}_{4}{ }^{-2}$ formları) tuzların etkisi araştırılmıştır. Farklı Cd dozları (0, 0.2 ve $1.0 \mathrm{mg} \mathrm{kg}^{-}$ $\left.{ }^{1}\right)$ ve farklı tuz formları altında $\left(\mathrm{NaCl}, \mathrm{Na}_{2} \mathrm{SO}_{4}\right.$ ve $\mathrm{CaCl}_{2}$ ) sera koşullarında 45 gün yetiştirilen makarnalık buğday yeşil aksam kuru madde üretiminde önemli farklılıkların olduğu tespit edilmiştir. Artan $\mathrm{Cd}, \mathrm{CaCl}_{2}$ uygulamaları dışındaki tüm tuz uygulamalarında bitkilerin kuru madde verimini azaltma eğilimi göstermiştir (Çizelge 2). Toprağa uygulanan tüm tuzlarda tuz uygulamasının yapılmadığı kontrol uygulamasına göre, kuru madde verimi azalmıştır. Bu azalışlar, en belirgin olarak Cl'nin $1000 \mathrm{mg} \mathrm{kg}^{-1}$ olarak verildiği $\mathrm{CaCl}_{2}$ ve $\mathrm{NaCl}$ uygulamalarında görülmüştür. Buna göre, toprağa Cd'un ve herhangi bir tuzun uygulanmadığı durumda bitkinin kuru madde verimi $438 \mathrm{mg}$ bitki $^{-1}$ iken, $1000 \mathrm{mg} \mathrm{kg}^{-1} \mathrm{NaCl}$ ve $500 \mathrm{mg} \mathrm{kg}^{-1} \mathrm{CaCl}_{2}$ uygulamasıyla bitkinin kuru madde verimi sırasıyla 310 ve 323 mg bitki ${ }^{-1^{\prime}}$ ye düştüğü bulunmuştur. Kadmiyumun 0.2 ve $1.0 \mathrm{mg} \mathrm{kg}^{-1}$ olarak verildiği ve $\mathrm{Cl}^{\prime}$ un $1000 \mathrm{mg} \mathrm{kg}^{-1}$ olarak $\mathrm{Na}^{+}$ve $\mathrm{Ca}^{+2}$ formunda uygulamalarıyla bitki kuru madde verimi daha çarpıcı biçimde düşmüştür (Çizelge 2). 
Çizelge 2. Farklı Cd dozları (0, 0.2 ve $1.0 \mathrm{mg} \mathrm{kg}^{-1}$ ) ve farklı tuz formları altında $\left(\mathrm{NaCl}, \mathrm{Na}_{2} \mathrm{SO}_{4}\right.$ ve $\left.\mathrm{CaCl}_{2}\right)$ sera koşullarında 45 gün yetiştirilen makarnalık buğday Diyarbakır-81 çeşidinin yeşil aksam kuru madde üretimi.

\begin{tabular}{|c|c|c|c|c|c|c|c|c|c|}
\hline \multirow{3}{*}{$\begin{array}{l}\text { Uygulamalar } \\
\text { mg kg-1-toprak }\end{array}$} & \multicolumn{9}{|c|}{ Yeșil Aksam Kuru Madde Üretimi, mg bitki ${ }^{-1}$} \\
\hline & \multicolumn{9}{|c|}{ Cd Uygulaması, $\mathrm{mg} \mathrm{kg}^{-1}$} \\
\hline & \multicolumn{3}{|c|}{$\underline{0}$} & \multicolumn{3}{|l|}{$\underline{0.2}$} & \multicolumn{3}{|l|}{$\underline{1.0}$} \\
\hline Kontrol & 438 & \pm & 2 & 433 & \pm & 12 & 423 & \pm & 32 \\
\hline $200 \mathrm{NaCl}$ & 346 & \pm & 18 & 340 & \pm & 10 & 332 & \pm & 28 \\
\hline $1000 \mathrm{NaCl}$ & 310 & \pm & 11 & 303 & \pm & 15 & 283 & \pm & 6 \\
\hline $100 \mathrm{Na}_{2} \mathrm{SO}_{4}$ & 402 & \pm & 25 & 389 & \pm & 26 & 382 & \pm & 31 \\
\hline $500 \mathrm{Na}_{2} \mathrm{SO}_{4}$ & 402 & \pm & 24 & 383 & \pm & 5 & 373 & \pm & 7 \\
\hline $100 \mathrm{CaCl}_{2}$ & 342 & \pm & 49 & 322 & \pm & 26 & 343 & \pm & 10 \\
\hline $500 \mathrm{CaCl}_{2}$ & 323 & \pm & 1 & 320 & \pm & 24 & 322 & \pm & 11 \\
\hline
\end{tabular}

Elde edilen sonuçlara göre, hem $\mathrm{Cd}$ hem de tuz stresi artınca makarnalık buğday yeşil aksam kuru madde verimi azalmıştır. Bu durum, bitkinin fizyolojik süreçlerinin olumsuz etkilenmesiyle açıklanmaktadır. Araştırma sonuçlarımızı destekleyen benzer bir araştırma da Shafi, M., ve ark. (2011) tarafından tespit edilmiştir. Araştırıcı, buğday bitkisini $\mathrm{NaCl}(75-150 \mathrm{mM})$ ve Cd $(2-4 \mu \mathrm{M})$ stresi altında yetiştirilmesi sonucunda yeşil aksam kuru madde veriminde düşüş olduğunu bildirmiştir. Debez ve ark. (2003) tarafından yapılan başka bir araştırmada da üç buğday çeşidinin $\mathrm{Cd}$ ve tuz stresi altında yetiştirmiştir. Buna göre, $\mathrm{Cd}$ ve tuzun ayrı ayrı ve ikisinin birlikte uygulamasıyla kuru madde veriminde ciddi azalışların olduğu, bu azalmanın tuz ve Cd'nin birlikte uygulandığında ise kuru madde veriminde azalmaların daha şiddetli olduğunu belirlemiştir. Mühling ve Lauchli, (2003) besin çözeltisi ortamına $10 \mu \mathrm{M} C d$ ve $75 \mu \mathrm{M} \mathrm{NaCl}$ uygulaması yaparak yetiştirdiği iki farklı buğday genotipinin kontrol bitkisine göre kuru madde veriminin azaldığı açıklanmıştır. Yapmış olduğumuz denemede $\mathrm{Cd}$ artan oranlarda tek başına uygulandığında kuru madde veriminde düşüş oluşturduğu, tuz ve $\mathrm{Cd}$ artan oranlarda birlikte olduğunda ise daha çarpıcı azalmaya sebep olduğu belirlenmiştir.

\section{Yeşil aksam Cd ve $\mathbf{Z n}$ konsantrasyonu}

Artan miktarda Cd uygulanmasıyla tüm tuz uygulamalarında bitkilerin $\mathrm{Cd}$ konsantrasyonu belirgin biçimde artmıştır. Ancak, bu artışlar ortama uygulanan tuzlardan farklı biçimde etkilenmiştir (Çizelge 3). Bitkinin yeşil aksamındaki $\mathrm{Cd}$ konsantrasyonunu etkilemede $\mathrm{Cl}^{-}$tuzlarının $\mathrm{SO}_{4}{ }^{-}$ 2 tuzlarına göre daha büyük rol oynadığı saptanmıştır (Çizelge 3). Klorürün varlığında ve artan oranda uygulanmasıyla (özellikle $\mathrm{Na}$ formunda) bitkilerin $\mathrm{Cd}$ konsantrasyonunda belirgin artışlar olmuştur. Tuz uygulamalarının yüksek dozu olan $1000 \mathrm{mg} \mathrm{kg}^{-1 \prime}$ lik $\mathrm{NaCl}$ ve $500 \mathrm{mg}$ $\mathrm{kg}^{-1}$ lik $\mathrm{Na}_{2} \mathrm{SO}_{4}$ uygulamalarında, dışardan $\mathrm{Cd}$ uygulanmadığında kontrol grubunda bitkinin yeşil aksamındaki $\mathrm{Cd}$ konsantrasyonu sırasıyla 0.13 ve $0.10 \mathrm{mg} \mathrm{kg}^{-1}$ düzeyinde olmuştur. Cd'un $0.2 \mathrm{mg} \mathrm{kg}^{-1}$ verildiği uygulamada aynı değerler sırasıyla 3.14 ve $2.30 \mathrm{mg} \mathrm{kg}^{-1}$ düzeyinde olduğu tespit edilmiştir. Kadmiyumun yüksek $1 \mathrm{mg} \quad \mathrm{Cd} \mathrm{kg}^{-1}$ dozunun uygulamasında ise sırasıyla 12.0 ve $9.7 \mathrm{mg} \mathrm{kg}^{-1}$ düzeyinde olmuştur. $\mathrm{NaCl}, \mathrm{CaCl}_{2}$ ve $\mathrm{NaSO}_{4}$ tuzlarının birlikte karşılaştırıldığında bitki $\mathrm{Cd}$ alımı üzerine olan etkilerinde $\mathrm{Cl}^{-}$tuzlarının $\mathrm{SO}_{4}{ }^{-2}$ tuzlarına göre daha büyük rol oynadığı saptanmıştır.

Çizelge 3. Farklı Cd dozları (0, 0.2 ve $\left.1.0 \mathrm{mg} \mathrm{kg}^{-1}\right)$ ve farklı tuz formları altında $\left(\mathrm{NaCl}, \mathrm{Na}_{2} \mathrm{SO}_{4}\right.$ ve $\left.\mathrm{CaCl}_{2}\right)$ sera koşullarında 45 gün yetiştirilen makarnalık buğday Diyarbakır-81 çeşidinin yeşil aksam Cd konsantrasyonu.

\begin{tabular}{|c|c|c|c|c|c|c|c|c|c|}
\hline \multirow{3}{*}{$\begin{array}{l}\text { Uygulamalar } \\
\text { mg kg-1-toprak }^{-1}\end{array}$} & \multicolumn{9}{|c|}{ Yeşil Aksam Cd Konsantrasyonu, mg kg ${ }^{-1}$} \\
\hline & \multicolumn{9}{|c|}{ Cd Uygulaması, $\mathrm{mg} \mathrm{kg}^{-1}$} \\
\hline & \multicolumn{3}{|c|}{0} & \multicolumn{3}{|l|}{0.2} & \multicolumn{3}{|l|}{1.0} \\
\hline Kontrol & 0.12 & \pm & 0.03 & 1.98 & \pm & 0.12 & 8.0 & \pm & 0.2 \\
\hline $200 \mathrm{NaCl}$ & 0.08 & \pm & 0.02 & 2.29 & \pm & 0.49 & 8.7 & \pm & 1.2 \\
\hline $1000 \mathrm{NaCl}$ & 0.13 & \pm & 0.01 & 3.14 & \pm & 0.47 & 12.0 & \pm & 1.5 \\
\hline $100 \mathrm{Na}_{2} \mathrm{SO}_{4}$ & 0.14 & \pm & 0.04 & 2.14 & \pm & 0.20 & 9.0 & \pm & 0.1 \\
\hline $500 \mathrm{Na}_{2} \mathrm{SO}_{4}$ & 0.10 & \pm & 0.02 & 2.30 & \pm & 0.39 & 9.7 & \pm & 1.1 \\
\hline $100 \mathrm{CaCl}_{2}$ & 0.09 & \pm & 0.02 & 1.91 & \pm & 0.20 & 5.9 & \pm & 0.5 \\
\hline $500 \mathrm{CaCl}_{2}$ & 0.13 & \pm & 0.01 & 2.43 & \pm & 0.26 & 8.3 & \pm & 0.7 \\
\hline
\end{tabular}


Sonuçlardan da görüldüğü gibi, her üç $\mathrm{Cd}$ uygulamasında da $\mathrm{Cl}^{-}$uygulaması altındaki bitkilerin $\mathrm{SO}_{4}^{-2}$ uygulanan bitkilere göre $\mathrm{Cd}$ konsantrasyonu daha yüksek bulunmuştur. Ancak Cl'un $\mathrm{Na}$ ve $\mathrm{Ca}$ formlarında uygulanması durumunda da bitkilerin Cd konsantrasyonu farklı şekilde etkilenmiştir. Klorurün $\mathrm{Cd}$ konsantrasyonu üzerindeki arttırıcı etkisi kendisini daha çok $\mathrm{Na}$ formunda uygulandığında göstermiştir. Kalsiyum varlığında Cl'nin Cd alımı üzerinde $\mathrm{Na}$ iyonuna göre daha az arttırıcı etki göstermesi, Ca'nın membranlar üzerinde koruyucu ve geçirgenliği kontrol edici etkisi ve $\mathrm{Ca}$ ile $\mathrm{Cd}$ arasında absorbsiyon sırasında bir antagonistik etkinin olmasıyla ilişkili olabilir. Son yıllarda, kadmiyumun insan sağlığına olumsuz etkilerinden dolayı değişik bitkilerde $\mathrm{Cd}$ alımı ve birikiminin nedenlerini belirlemeye yönelik araştırmalar hızla artmaktadır. Bu kapsamda, bitkilerde Cd'nin yüksek miktarda alımlarında etkili olan toprak tuzluluğunun ilişkisi giderek artan düzeyde araştırılmaktadır. Dünya topraklarında tuzluluğun giderek artış göstermesi ve topraklara gübreleme veya endüstriyel atıklarla $\mathrm{Cd}$ girişinin artması bu ilişkiyi önemli kılmaktadır. Topraktaki tuzluluğun (özellikle Cl’nin) bitkilerde $\mathrm{Cd}$ birikimini etkileyen en önemli faktör olduğu yapılan çalışmamızda belirlenmiştir. Özellikle, kadmiyumun $\mathrm{Cl}$ ile yaptığı kompleksler sonucunda katyon değiştirici yüzeylere tutunması azalmakta ve böylece bitkilerce alınma şansının daha fazla olduğu düşünülmektedir. Bu durum, klor ile Cd'nin kompleksleşmesi sonucuda Cd'un toprakta daha fazla hareketli olması ve plazma membranlar üzerindeki absorbsiyon noktalarına daha hızlı hareket etmesiyle açıklanabilir (McLaughlin ve ark., 1996; Smolders ve McLaughlin, 1996). Elde ettiğimiz bulgularımızın literatürde yapılan çalışmalarla uyumlu olduğu saptanmıştır. Söz konusu araştırmalarda, topraktaki tuzluluğun $\mathrm{NaCl}$ olarak artırılmasıyla toprak çözeltisinde çözünür $\mathrm{Cd}$ konsantrasyonunun yükseldiği, ancak $\mathrm{NaCl}$ yerine $\mathrm{NaNO}_{3}$ uygulanması durumunda ise toprak çözeltisindeki çözünür $\mathrm{Cd}$ miktarında herhangi bir değişikliğin olmadığı belirlenmiştir (Smolders ve ark., 1998). Wu ve ark. (2002) survey amaçlı yaptıkları araştırmada, buğday tane Cd konsantrasyonu ile tuzluluk ve diğer toprak özellikleri arasındaki ilişkiyi belirlemiştir. Tuzluluğun ve özellikle $\mathrm{Cl}^{-}$anyonunun yüksek olduğu alanlarda makarnalık buğday tanesinde $\mathrm{Cd}$ konsantrasyonunun daha fazla olduğu görülmüştür. Norvell ve ark. (2000) tarafından yapılan survey niteliğindeki bir araştırmada, topraktaki $\mathrm{Cl}^{-}$konsantrasyonunun artmasıyla makarnalık buğdaylarda tanede Cd konsantrasyonunun arttığı saptanmıştır. Zhong-Qio ve ark. (2003) tarafından sera koşullarında yazlık buğday çeşitleriyle yapılan bir araştırmada ise, toprağa eşit oranda $\mathrm{K}^{\prime}$ un $\mathrm{NO}_{3}^{-}, \mathrm{SO}_{4}{ }^{-2}$ ve $\mathrm{Cl}^{-}$ tuzlarının uygulanması sonucunda, buğday bitkisinin yeşil aksamında $\mathrm{Cd}$ alımının $\mathrm{Cl}^{-}$ve $\mathrm{SO}_{4}^{-2}$ ile daha fazla arttığı açıklanmıştır. Abbas ve ark. (2018) tarafından yapılan araştırmada buğday bitkisinde tuz ve $\mathrm{Cd}$ stresini tek tek ve birlikte etkilerini karşılaştırmıştır. Tuz stresinin Cd stresine göre bitki büyümesini, tane verimini ve klorofil içeriğini azalttığını bildirmiştir. Ayrıca, bu iki stresin birlikte olduğu durumlarda bitki büyümensin daha şiddetli etkilendiği açıklanmıştır. Gerçekten, toprak ve bitkilerde giderek artan bir Cd kontaminasyonu söz konusudur (Grant ve ark., 1998). Özellikle topraklarda yüksek tuzluluğun olduğu alanlarda yetişen bitkilere $\mathrm{Cd}$ daha fazla alınması olası görülmektedir. Artan $\mathrm{Cd}\left(0,0.2\right.$ ve $\left.1.0 \mathrm{mg} \mathrm{kg}{ }^{-1}\right)$ dozları altında yeşil aksam $\mathrm{Zn}$ konsantrasyonu sırasıyla 22, 22 ve $20 \mathrm{mg} \mathrm{kg}^{-1}$ olduğu saptanmıştır. Farklı tuz uygulamalarına bağlı olarak yeşil aksam Cd konsantrasyonunun artmasına bağlı olarak Zn konsantrasyonunda da artışlar olduğu tespit edilmiştir. Örneğin, $\mathrm{NaCl}$ ve $\mathrm{Na}_{2} \mathrm{SO}_{4}$ en yüksek dozlarında bitkideki $\mathrm{Cd}$ konsantrasyonunun artmasıyla Zn konsantrasyonuda sırasıyla 23, 26, 28 ve $25,26,23 \mathrm{mg} \mathrm{kg}^{-1}$ düzeyine arttığı belirlenmiştir (Çizelge 4). Kadmiyum ve $Z n$ 'nin bazı kimyasal özellikler yönünden benzer olması nedeniyle $\mathrm{Cd}$ ve $\mathrm{Zn}$ arasından antagonistik ve sinergistik ilişki olabilmektedir. Genellikle birçok araştırıcı tarafından değişik bitkilerdeki Zn'nun Cd alımını üzerine antagonistik etkisinin olduğu açıklanmıştır (Özkutlu ve Kara, 2018). Ancak, bitkilerde Zn'nun Cd alımı üzerine olan antagonistik etkisine karşı sinergistik etkisi olduğunu gösteren araştırma sonuçları da bulunmaktadır. Elde ettiğimiz sonuçları destekleyen bir araştırmada sinergistik etkinin olduğu bildirilmiştir. Örneğin survey amaçlı bir araştırmada buğday ve toprak örneklerinin analizi sonucunda, tarla koşullarında $\mathrm{Cd}$ ve $\mathrm{Zn}$ elementlerinin yüksek miktarlarda birlikte bulunduğu yerlerde bitkilerde bu elementlerin biriktiği ve Cd-Zn etkileşiminin sinergistik bir süreç içinde olduğu bildirilmiştir (Nan ve ark., 2002). 
Çizelge 4. Farklı Cd dozları ( $0,0.2$ ve $1.0 \mathrm{mg} \mathrm{kg}^{-1}$ ) ve farklı tuz formları $\left(\mathrm{NaCl}, \mathrm{Na}_{2} \mathrm{SO}_{4}\right.$ ve $\left.\mathrm{CaCl}_{2}\right)$ altında sera koşullarında 45 gün yetiştirilen makarnalık buğday Diyarbakır-81 çeşidinin yeşil aksam Zn konsantrasyonu.

\begin{tabular}{|c|c|c|c|c|c|c|c|c|c|}
\hline \multirow{3}{*}{$\begin{array}{l}\text { Uygulamalar } \\
\mathrm{mg} \mathrm{kg}^{-1} \text {-toprak }\end{array}$} & \multicolumn{9}{|c|}{ Yeşil Aksam Zn Konsantrasyonu, mg kg ${ }^{-1}$} \\
\hline & \multicolumn{9}{|c|}{ Cd Uygulaması, $\mathrm{mg} \mathrm{kg}^{-1}$} \\
\hline & \multicolumn{3}{|c|}{0} & \multicolumn{3}{|c|}{0.2} & \multicolumn{3}{|c|}{1.0} \\
\hline Kontrol & 22 & \pm & 1 & 22 & \pm & 1 & 20 & \pm & 2 \\
\hline $200 \mathrm{NaCl}$ & 22 & \pm & 3 & 30 & \pm & 1.2 & 21 & \pm & 2 \\
\hline $1000 \mathrm{NaCl}$ & 23 & \pm & 1 & 26 & \pm & 2 & 28 & \pm & 6 \\
\hline $100 \mathrm{Na}_{2} \mathrm{SO}_{4}$ & 23 & \pm & 1 & 22 & \pm & 1 & 22 & \pm & 0 \\
\hline $500 \mathrm{Na}_{2} \mathrm{SO}_{4}$ & 25 & \pm & 2 & 26 & \pm & 1 & 23 & \pm & 0 \\
\hline $100 \mathrm{CaCl}_{2}$ & 20 & \pm & 1 & 22 & \pm & 2 & 20 & \pm & 2 \\
\hline $500 \mathrm{CaCl}_{2}$ & 26 & \pm & 3 & 23 & \pm & 1 & 19 & \pm & 2 \\
\hline
\end{tabular}

\section{Sonuç ve Öneriler}

$\mathrm{Bu}$ araştırmada, makarnalık buğday (Diyarbakır-81) bitkisinin ortamdan $\mathrm{Cd}$ alımı ve bünyesinde $\mathrm{Cd}$ biriktirmesi üzerine $\mathrm{Cl}^{\prime}$ un artırıcı etkisi olduğu tespit edilmiştir. Farklı tuzların katyonlarından $\mathrm{Na}^{+}$ve $\mathrm{Ca}^{+2}$ formları arasında da $\mathrm{Cd}$ konsantrasyonunu en fazla arttırmada $\mathrm{Na}^{+}$olduğu ardından $>\mathrm{Ca}^{+2}$ belirlenmiştir. Ayrıca, $\mathrm{Cl}^{-}$tuzlarının $\mathrm{SO}_{4}{ }^{-2}$ tuzlarına göre yeşil aksam $\mathrm{Cd}$ konsantrasyonunu daha fazla arttırdığı saptanmıştır. Tuz uygulamalarının $\left(\mathrm{NaCl}, \mathrm{Na}_{2} \mathrm{SO}_{4}\right.$ ve $\mathrm{CaCl}_{2}$ ) tersine $\mathrm{Zn}$ uygulaması bitkilerin $\mathrm{Cd}$ miktarı üzerinde düşürücü etki yapmıştır. Çinkonun bu etkisi ileride daha ayrıntılı incelenmiştir. Kadmiyum ile kirlenmiş ve tuzluluğu yüksek topraklarda yetiştirilen bitkilerde $\mathrm{Cd}$ analizleri mutlaka yapılmalıdır. Kadmiyum ve tuzluluk stresine dayanıklı olan çeşitlerin belirlenmesine yönelik araştırmalara özel önem verilmelidir.

Çıkar Çatışması Beyanı: Makale yazarları aralarında herhangi bir çıkar çatışması olmadığını beyan ederler.

\section{Araştırmacıların Katkı Oranı Beyan Özeti:}

Yazarlar makaleye eşit oranda katkı sağlamış olduklarını beyan ederler.

\section{Kaynaklar}

Abbas, T., Rizwan, M., Ali, S., Adrees, M., Zia-urRehman, M., Qayyum, M. F. and Murtaza, G. 2018. Effect of biochar on alleviation of cadmium toxicity in wheat (Triticum aestivum L.) grown on Cd-contaminated saline soil. Environmental Science and Pollution Research, 25 (26): 25668-25680.
Adams, M.L., Zhao, F.J., McGrath, S.P., Nicholson, F.A. and Chambers, B.J. 2004. Predicting cadmium concentrations in wheat and barley grain using soil properties. J Environ. Qual., 33: 532-541.

Bernard, A. 2008. Cadmium and its adverse effects on human health. Indian Journal of Medical Research, 128 (4): 557.

Bouyoucous, G.J. 1952. Hydrometer method improved for making particle size at analysis of soil. Argon. J., 54(5):464-465.

Clemens, S. 2006. Toxic metal accumulation, responses to exposure and mechanisms of tolerance in plants. Biochimie, 88: 17071719.

Çağlar, K.Ö. 1949. Toprak Bilgisi. Ankara Üniveristesi Ziraat Fakültesi Yayınları, Ankara.

Debez, A.,W., Chaibi, and Bouzid, S. 2003. Physiological responses and structuralmodifications in Atriplex halimus L. plants exposed to salinity. In: Cash Crop Halophytes: Recent Studies, eds. L. Helmut and M. Marina, pp. 19-30. Dordrecht, the Netherlands: Kluwer.

EEC, 2001. Commission Regulation (EC) no. 466/2001 of 8 March 2001 setting maximum levels for certain contaminants in foodstuffs. Official Journal of the European Communities, 16.3.2001, L77/ 1-23.

Ekbic, E., Cagıran, C., Korkmaz, K., Kose, M. A., and Aras, V. 2017. Assessment of watermelon accessions for salt tolerance using stress tolerance indices. Ciência e Agrotecnologia, 41(6), 616-625.

FAO, 2001. Food and agriculture organization of the United Nations. http://faostat.fao.org.

Gallego, S.M., Pena, L.B., Barcia, R.A., Azpilicueta, C.E., Iannone, M.F., Rosales, E.P., Zawoznik, M.S., Groppa, M.D. and Benavides, M.P. 
2012. Unravelling cadmium toxicity and tolerance in plants: insight into regulatory mechanisms. Environ. Exp. Bot., 83: 33-46.

Gawalko, E.J., Garrett, R.G. and Nowicki, T.W. 2001. Trace elements in western Canadian hard red spring wheat (Triticum aestivum L.): levels and quality assurance. Journal of AOAC International, 84 (6): 1953-1963.

Grant, C.A., Buckley, W.T., Bailey, L.D. and Selles, F. 1998. Cadmium accumulation in crops. Canadian Journal of Plant Science, 78 (1): 1-17.

Gray, C.W., McLaren, R.G. and Roberts, A.H.C. 2001. Cadmium concentrations in some New Zealand wheat grain. New Zealand Journal of Crop and Horticultural Science, 29 (2): 125-136.

Greger, M. and Löfstedt, M. 2004. Comparison of uptake and distribution of cadmium in different cultivars of bread and durum wheat. Crop Science, 44 (2): 501-507.

Greger, M. and Landberg, T. 2008. Role of rhizosphere mechanisms in $\mathrm{Cd}$ uptake by various wheat cultivars. Plant and Soil, 312 (1-2): 195-205.

Hart, J.J., Welch, R.M., Norvell, W.A. and Kochian, L.V. 2002.Transport interactions between cadmium and zinc in roots of bread and durum wheat seedlings. Physiol. Plant, 116: 73-78.

Jackson, M.L. 1959. Soil chemical analysis. Englewood Cliffs, New Jersey.

Kılıç, R. ve Korkmaz, K. 2012. Kimyasal Gübrelerin Tarım Topraklarında Artık Etkileri. Biyoloji Bilimleri Araştırma Dergisi, 5(2): 87-90.

Korkmaz, K., Kara, S.M., Özkutlu, F. and Gul, V. 2010. Monitoring of heavy metals and selected micronutrients in hempseeds from North-western Turkey. African Journal of Agricultural Research, 5(6): 463-467.

Korkmaz, K., Ertürk, Ö., Ayvaz, M. Ç., Özcan, M. M., Akgün, M., Kirli, A., and Alver, D. O. 2018. Effect of cadmium application on antimicrobial, antioxidant and total phenolic content of basil genotypes. Indian Journal of Pharmaceutical Education and Research, 52(4): 108-114.

Lindsay, J. 1979. The Trent and Mersey Canal, David \& Charles, Newton Abbot.

Lindsay, W.L. and Norvell, W.L. 1978. Development of a DTPA soil test for zinc, iron, manganese, copper. Soil Science Society of America Journal, 42:421-428.

Mclaughlin, M.J., Tiller, K.G. and Smart, M.K. 1997. Speciation of cadmium in soils solution of saline/sodic soils and relationship with cadmium concentrations in potato tubers. Australian Journal of Soil Research, 35: 1-17.

McLaughlin, M.J., Tiller, K.G., Beech, T.A. and Smart, M.K., 1994. Soil salinity causes elevated cadmium concentrations in fieldgrown potato tubers. J. Environ. Qual., 23 (5): 1013-1018.

McLaughlin, M.J., Tiller, K.G., Naidu, R. and Stevens, D.G. 1996. Review: The behaviour and environmental impact of contaminants in fertilizers. Aust. J. Soil Res., 34: 1-54.

Moral, R., Gilkes, R.J. and Moreno-Caselles, J. 2002. A comparison of extractants for heavy metals in contaminated soils from Spain. Communications in Soil Science and Plant Analysis, 33 (15-18): 2781-2791.

Mühling, K.H. and Lauchli, A. 2003. Interaction of $\mathrm{NaCl}$ and $\mathrm{Cd}$ stress on compartmentation pattern of cations, antioxidant enzymes and proteins in leaves of two wheat genotypes differing in salt tolerance. Plant Soil, 253(1): 219-231.

Nan, Z., Li, J., Zhang, J. and Cheng, G. 2002. Cadmium and zinc interactions and their transfer in soil-crop system under actual field conditions. Science of the Total Environment, 285 (1-3): 187-195.

Norvell, W.A., Wu, J., Hopkins, D.G. and Welch, R.M. 2000. Association of cadmium in durum wheat grain with soil chloride and chelate-extractable soil cadmium. Soil Science Society of America Journal, 64:2162-8.

Özkutlu, F., Turan, M., Korkmaz, K. and Huang, Y. M. 2009. Assessment of heavy metal accumulation in the soils and hazelnut plant (Corylus avellena L.) from Black Sea coastal region of Turkey. Asian Journal of Chemistry, 21(6), 4371-4388.

Özkutlu, F. and Kara, Ş.M. 2018. The effect of zinc (Zn) fertilization on alleviating cd accumulation in durum wheat grain. Journal of Agricultural Science and Technology B, 8 (2018): 203-208.

Özkutlu, F. and Kara, Ş.M. 2019. Cd concentration of durum wheat grain as influenced by soil salinity. Akademik Ziraat Dergisi, 8 (1): 97100.

Quinn, C. J., Mohammad, A. and Macfie, S.M. 2011. Accumulation of cadmium in near-isogenic lines of durum wheat (Triticum turgidum L. var durum): the role of transpiration. Physiology and Molecular Biology of Plants, 17 (4): 317.

Schlichting, E. and Blume, H.P. 1966. Bodenkundliches praktikum. verlag paul parey. Hamburg- Berlin. 
Shafi, M., Bakht, J., Raziuddin, Y, Hayat and Zhang, G. 2011. Genotypic differences in the inhibition of photosynthesis and chlorophyll fluorescence by salinity and cadmium stresses on stresses in wheat. Journal of Plant Nutrition, 34: 315-23.

Shentu, J., He, Z., Yang, X.E. and Li, T. 2008. Accumulation properties of cadmium in a selected vegetable-rotation system of southeastern China. Journal of Agricultural and Food Chemistry, 56 (15): 6382-6388.

Smolders, E. and McLaughlin, M.J., 1996. Effect of $\mathrm{Cl}$ on $\mathrm{Cd}$ uptake by Swiss chard in nutrient solutions. Plant Soil, 179: 57-64.

Smolders, E., Lambregts, R.M., McLaughlin, M.J., Tiller. and K.G. 1998. Effect of soil solution chloride on cadmium availability to Swiss chard. Journal of Environmental Quality, 27 (2): 426-431.

U. S. Salinity Laboratory Staff. 1954. Diagnosis and improvement of saline and alkaline soils (Ed
L. A. Richards). USDA Agriculture Handbook B, No: 60, U. S. Gov. Printing Office, Washington, 160P.

Uyanık, M., Kara, S.M. ve Korkmaz, K. 2014. Bazı kışlık kolza (Brassica napus L.) çeşitlerinin çimlenme döneminde tuz stresine tepkilerinin belirlenmesi. Journal of Agricultural Sciences, 20 (4): 368-375.

Weggler-Beaton, K., McLaughlin, M.J. and Graham, R.D. 2000. Salinity increases cadmium uptake by wheat and Swiss chard from soil amended with biosolids. Austr. J. Soil Res, 38 (1): 37-45.

WHO, 2001. World health organization. http://who.org.

Wu, J., Norvell, W.A., Hopkins, D.G. and Welch, R.M. 2002. Spatial variability of grain cadmium and soil characteristics in a durum wheat field. Soil Science Society of America Journal, 66:268-75. 